\title{
Severe hearing loss in seniors: Surgical risks and audiological outcome after cochlear implantation
}

\author{
Kerstin Stähr $^{1 *}$, Judith Arnolds ${ }^{1}$, Patrick Munder ${ }^{1}$, Heike Bagus ${ }^{2}$, Michael Günnicker ${ }^{3}$, Stephan Lang ${ }^{1}$ and Diana Arweiler-Harbeck ${ }^{1}$ \\ ${ }^{1}$ Department of Otorhinolaryngology, Head and Neck Surgery, University Hospital of Essen \\ ${ }^{2} \mathrm{CIC}$ Ruhr Rehabilitation, Essen \\ ${ }^{3}$ Department of Anesthesiology University Hospital of Essen
}

\begin{abstract}
Background: Aim of study was the evaluation of hearing improvement, quality of life and surgical risks in geriatric patients receiving a cochlear implant.

Material and methods: 78 postlingual deafened patients older than 60 years (yrs) implanted between 2007 and 2012. The cohort was divided into 60-69 yrs (G II, $\mathrm{n}=35)$ and $>70$ yrs (G III, $\mathrm{n}=43$ ). Subjective improvement in different everyday surroundings was evaluated by APHAB questionnaire. Improvement in quality of life was assessed by a QoL questionnaire. Preoperative risk factors and perioperative complications were analyzed via retrospective chart review. All subjects were categorized preoperatively according to ASA-Criteria. Audiological improvement was tested by Freiburger speech test for mono- and bisyllables. Results were compared to a younger control group aged 40-59 yrs ( $\mathrm{G} \mathrm{I}, \mathrm{n}=39$ ) having received $\mathrm{CI}$ in comparable conditions. 117 patients were included.

Results: According to APHAB questionnaire all groups had a significant increase in perception in everyday surroundings. An improvement in quality of life was reported in all groups. No increase in surgical complications in the older groups was recorded. Seniors at age 60-69 yrs. do not differ from a younger control. No difference in speech perception was shown for bisyllabic words in G I, II, and III $(98 \%, 65 \mathrm{~dB})$. G III showed a lower perception for monosyllabic words ( $53 \%, 65 \mathrm{~dB})$ than G I $(63 \%, 65 \mathrm{~dB})$ and $\mathrm{G} \mathrm{II}(58 \%, 65 \mathrm{~dB})$.
\end{abstract}

Conclusion: Geriatric patients over 70 yrs. significantly benefit from cochlear implantation, though outcome in speech perception is marginally inferior to younger patients.

\section{Introduction}

Severe hearing loss often is accompanied by social isolation and a decrease in quality of life. Cochlear Implantation (CI) is a scientifically well researched tool for rehabilitation of speech perception $[1,2]$. Demographic development in the western civilization leads to an increase of $65+$ year olds. Due to this fact the number of patients with severe hearing loss, in the majority of cases caused by presbycusis, is rising. Communication inability leads to social isolation, depression and progressive dementia in geriatric patients [3]. Seniors request age appropriated quality of life including best possible communication abilities in public. Consequently there is a higher demand on cochlear implantation in this population group [4]. On the other hand performing surgery in older patients often goes along with a higher risk of complications caused by the procedure itself or anesthesia. Thus benefit from implantation on the one hand and surgical risk on the other has to be calculated carefully.

The elderlies' speech performance after CI is usually highly satisfactory. However there is a discrepancy in research regarding performance in old patients compared to a younger control. Some authors describe no difference in the two groups [5,6] while others found poorer results in seniors $[7,8]$. This could be derived from an inconsistent inclusion age for seniors in each study and a heterogeneous collective.

This study aims at evaluation of post- and perioperative risks and improvement in audiological performance in seniors compared to younger CI patients. A possible improvement in quality of life caused by the hearing improvement is assessed by a questionnaire. Seniors were divided into two subgroups for further specification of age effects on speech perception. To evaluate subjective benefit in everyday situations the APHAB questionnaire was used.

\section{Material and methods}

This study was performed in accordance with the Declaration of Helsinki and was approved by the local ethics committee. Retrospective analysis of patients' charts as well as prospective evaluation of questionnaires was included. Informed consent was obtained from all individual participants included in the study. 117 patients, who were implanted between 2007 and 2013 and older than 60 years were included. For a better distinction subjects were divided into one group aged 60-69 (G II) and one group aged more than 70 years (G III), G II containing 35 and G III 43 seniors. The duration of profound hearing impairment averaged 29 yrs. for G II and 20 yrs. for G III. Preoperative evaluation showed a profound hearing loss in pure tone audiometry

Correspondence to: Dr. med. Kerstin Stähr, Department of Otorhinolaryngology, Head and Neck Surgery University Hospital of Essen, Hufelandstr 55, 45147 Essen, Germany; Tel: 0049/201-7232971; Fax: 0049/201-7235903; E-mail: kerstin.staehr@uk-essen.de

Key words: cochlear implantation, seniors, quality of life, hearing improvement, surgical risk

Received: July 16, 2016; Accepted: August 08, 2016; Published: August 13, 2016 
and a speech recognition less than $40 \%$ at $65 \mathrm{~dB}$ (Freiburger Speech test) with optimal fitted hearing aids. Only patients with slow progredient hearing loss, presbyacusis or acute hearing loss were included. Patients suffering from a syndrome or a longtime hearing loss without hearing aid supply were excluded. Control group (G I) included 40-59 year old subjects fulfilling the same inclusion criteria (Table 1). Patient' data and speech perception of the octogenarians were listed separately (Table 2).

For assessment of surgical risks, peri- and postoperative complications were collected retrospectively. Hematoma, vertigo, wound infection and partial temporal facial weakness were defined as complications. All patients were categorized according to the ASA classification system $(9,10)$, a validated predictor for peri- and postoperative complications [11], (Figure 1).

Subjective speech perception in everyday environment with and without CI was investigated using the Abbreviated Profile of Hearing Aid Benefit (APHAB) questionnaire. This test contains 24 questions covering ease of communication (EC), speech recognition in reverberation (RV), background noise (BK) and evasiveness to sound (AV). Communication problems in different situations are rated from 0 to 100 . To evaluate subjective benefit in social relationships, all subjects received a quality of life questionnaire. This questionnaire was developed by the authors.

Audiological outcome was tested by Freiburger speech test for mono- and bisyllabic words and Oldenburger sentence test in quiet and noise (OLSA) before and up to one year after surgery. This test is comprised of random lists of words being presented to the subject at $65 \mathrm{~dB}$. Only patients with a set of complete audiometrical data from 3 ,
6 and 12 months after implantation were included. Improvement in speech perception was tested unilaterally.

Data analysis for speech perception and APHAB questionnaire was performed with Mann-Whitney-U-Test for comparison of the different groups and Wilcoxon signed-rank test for the different measurement points. Statistical significance was accepted at a $\mathrm{p}<0.05$ level.

\section{Results}

\section{Complications and surgical risk profile}

ASA classification ranged from 1 to 3 . Surgical risk for patients in group III was estimated higher than for the other groups. In G III $35 \%$ of the patients were rated ASA 3 and 5\% ASA 1 while in G II $14 \%$ and in G I 8\% were assigned class ASA 3 (Figure 1). In accordance to ASA classification the incidence of preoperative risk factors like heart and lung diseases and diabetes mellitus was highest in G III. None of the patients had to be excluded from surgery due to a high surgical risk. There were no major complications during surgery or in the postoperative phase. One patient (G II) suffered from paresthesia of the right arm and was monitored on the intensive care unit for one night. He recovered completely within a few days, while an ischemia was excluded via CT scan. One patient using permanent anticoagulation suffered a hematoma requiring surgery (G II). Typical complications after cochlear implantation, for example vertigo, partial facial weakness or wound infection occurred rarely and equally in all subgroups (Table 1).

\section{APHAB and quality of life questionnaire}

Referring to Cox et al. a difference of more than $10 \%$ in APHAB

Table 1. Study cohort.

\begin{tabular}{|c|c|c|c|}
\hline & group I & group II & group III \\
\hline & $40-59 \mathrm{yrs}$ & $60-69 \mathrm{yrs}$ & $>70 \mathrm{yrs}$ \\
\hline \multicolumn{4}{|l|}{ characteristics } \\
\hline numbers (n) & 39 & 35 & 43 \\
\hline mean age (yrs.) (range) & $51.3(43-59)$ & $65.2(60-69)$ & $74.1(70-88)$ \\
\hline gender male/female (n) & $27 / 12$ & $16 / 19$ & $20 / 23$ \\
\hline mean length of hospital stay (d) (range) & $4.9(4-7)$ & $5.2(4-10)$ & $5(4-7)$ \\
\hline \multicolumn{4}{|l|}{ complications $(\%(\mathrm{n}))$} \\
\hline $\begin{array}{l}\text { hematoma } \\
\text { - with/without surgical intervention }\end{array}$ & $7.8(3) / 0$ & $5.7(2) / 2.9(1)$ & $2.3(1) / 0$ \\
\hline vertigo & $7.8(3)$ & $2.9(1)$ & $6.9(3)$ \\
\hline $\begin{array}{l}\text { facial weakness } \\
\text { - immediate/delayed }\end{array}$ & $0 / 2.6(1)$ & $0 / 2.9(1)$ & $0 / 0$ \\
\hline wound infection & 0 & 0 & $2.3(1)$ \\
\hline \multicolumn{4}{|l|}{ risk factors $(\%(\mathrm{n}))$} \\
\hline hypertension & $25.6(10)$ & $42.8(15)$ & $48.8(21)$ \\
\hline coronary artery disease/heart failure & $5.1(2)$ & $14.3(5)$ & $27.9(12)$ \\
\hline cardiac arrhythmia & $5.1(2)$ & $5.7(2)$ & $25.6(11)$ \\
\hline renal failure & 0 & 0 & $2.3(1)$ \\
\hline pulmonary disease & $12.8(5)$ & $5.7(2)$ & $16.3(7)$ \\
\hline diabetes mellitus & 0 & $5.7(2)$ & $9.3(4)$ \\
\hline
\end{tabular}

Table 2. Octogenarians: Patient data and speech perception.

\begin{tabular}{|c|c|c|c|c|c|c|c|c|c|}
\hline \multirow[t]{2}{*}{ pt. } & \multirow[t]{2}{*}{$\begin{array}{c}\text { age } \\
\text { (yrs.) }\end{array}$} & \multirow[t]{2}{*}{ gender } & \multirow[t]{2}{*}{ complications } & \multicolumn{2}{|c|}{$\begin{array}{c}\text { FST - } 3 \text { mo. } \\
(65 \mathrm{~dB})\end{array}$} & \multicolumn{2}{|c|}{$\begin{array}{l}\text { FST - } 6 \text { mo. } \\
\text { (65dB) }\end{array}$} & \multicolumn{2}{|c|}{$\begin{array}{c}\text { FST }-12 \mathrm{mo} \\
\quad(65 \mathrm{~dB})\end{array}$} \\
\hline & & & & ms & bs & ms & bs & ms & bs \\
\hline 1 & 88 & $\mathrm{~m}$ & minor wound-infection & $100 \%$ & $50 \%$ & $100 \%$ & $45 \%$ & $100 \%$ & $60 \%$ \\
\hline 2 & 80 & $\mathrm{f}$ & none & $60 \%$ & $15 \%$ & $100 \%$ & $25 \%$ & 100 & $5 \%$ \\
\hline 3 & 84 & $\mathrm{f}$ & none & $100 \%$ & $50 \%$ & $100 \%$ & $50 \%$ & 100 & $50 \%$ \\
\hline 4 & 86 & $\mathrm{f}$ & none & $100 \%$ & $15 \%$ & $100 \%$ & $50 \%$ & 100 & $50 \%$ \\
\hline
\end{tabular}

pt.: Patient, m: male, f: female, FST: Freiburger speech test, ms: monosyllabic, bs: bisyllabic 


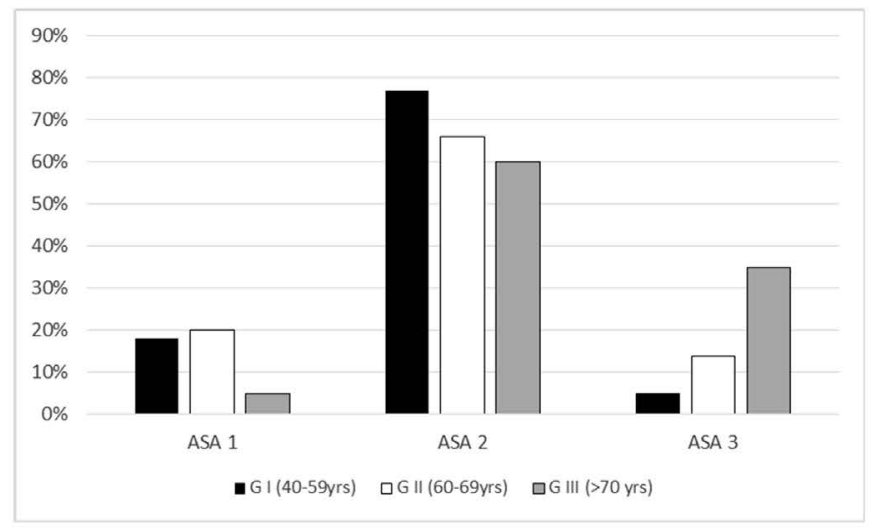

A

\begin{tabular}{|ll}
\hline ASA I & normal healthy patient \\
ASA II & patient with mild systemic disease \\
ASA III & patient with severe systemic disease \\
ASA IV & $\begin{array}{l}\text { patient with severe systemic disease } \\
\text { that is a constant threat to life }\end{array}$ \\
ASA V & $\begin{array}{l}\text { moribund patient who is not } \\
\text { expected to survive without the } \\
\text { operation }\end{array}$ \\
ASA VI & $\begin{array}{l}\text { declared brain-dead patient whose } \\
\text { organs are being removed for donor } \\
\text { purposes }\end{array}$
\end{tabular}

B

Figure 1. Distribution of ASA classification, $* \mathrm{p}<0,05, * * * \mathrm{p}<0,01$.

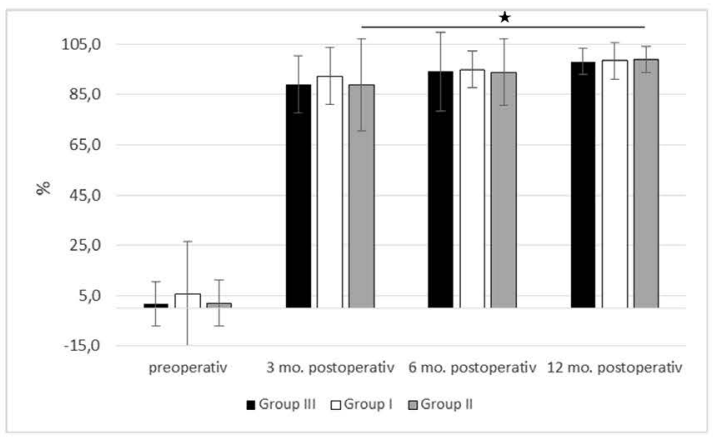

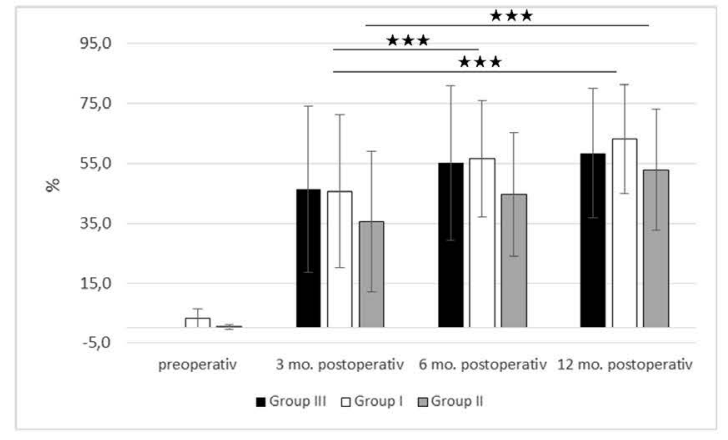

B

Figure 2. Freiburger speech test $(65 \mathrm{~dB}),{ }^{*} \mathrm{p}<0.05, * * * \mathrm{p}<0.01$, not marked: increase of perception preoperative - postoperative highly significant $(\mathrm{p}<0.01)$.

questionnaire correlates to a significant difference within a $95 \%$ interval [12].

Hearing performance with CI was judged by the subjects to be significantly better than without CI in all subgroups $(\mathrm{p}<0.05)$. As shown in figure 4 communication in a quiet surrounding (EC), in a surrounding with hall (RV) and with background noise (BN) was rated significantly $(\mathrm{p}<0.05)$ better after implantation in all groups. The subjects reported more difficulty in understanding with background noise with CI than in the other scenarios. Aversiveness showed a significant increase with cochlear implant $(\mathrm{p}<0.05)$. Comparing the subgroups there was no difference between G I and G II with CI. G III reported more conversational problems in all settings (EC, RV, $\mathrm{BN})$ than the other groups, being significant for $\mathrm{EC}$ and $\mathrm{RV}(\mathrm{p}<0.05)$. Aversiveness was judged similarly in all three groups.

Result of quality of life questionnaire was a high satisfaction after CI implantation. There was no significant difference in the three groups, even though positive change pertaining to social integration was highest in patients older than 70 yrs (Table 2).

\section{Audiological outcome}

Only patients with complete audiological examinations preoperatively and 3, 6 and 12 months postoperatively were included. Preoperatively the majority was not able to reproduce mono- and bisyllabic words at $65 \mathrm{~dB}$ with optimized hearing aid. Two subjects showed a $10 \%$ speech perception for bisyllabic words. Speech perception increased after cochlear implantation for all subgroups significantly.
All of them showed a further increase after 6 and 12 months. There was no significant difference between the three groups.

Speech perception one year after implantation for bisyllabic words was at $98 \%$ for all subgroups. Test results improved significantly in all groups and all measured parameters after implantation ( $<<0.01$, figure 2 ). In addition G III showed significant improvement comparing results 3 and 12 months postoperatively $(\mathrm{p}<0.05)$. Differences in G I and G II were not significant.

Speech perception for monosyllabic words one year after implantation was $63 \%$ in G I, 53\% in G III and 58\% in G I though with no statistically relevant difference (Figure 2). Postoperatively patients in G I and II showed a better performance than G III. Comparing the different measuring points G II showed significant increase of speech perception at 3, 6 and 12 month ( $\mathrm{p}<0.01$ ), G III at 3 and 12 month $(\mathrm{p}<0.01)$ and $\mathrm{G}$ I showed no significant difference. Test results improved significantly in all groups and all measuring points after implantation $(\mathrm{p}<0.01)$. Due to retrospective data analysis, OLSA was performed under different conditions as in quiet surrounding or in noise and with or without additional hearing aid. For that reason only patients with complete OLSA data set tested unilaterally in noise were included (G I 75\%, G II 76\%, G III 72\%). No significant difference between the test results in the different groups was found. Comparing the different measuring points $G$ I showed no significant difference, $G$ II at 3 and $6(\mathrm{p}<0.01)$ and 3 and 12 month $(\mathrm{p}<0.05)$ and G III at 3 and 12 month $(\mathrm{p}<0.05)$. All groups showed a significant increase in hearing performance after implantation $(\mathrm{p}<0.01)$. 


\section{Outcome in octogenarians}

Our collective comprised four patients older than 80 yrs (Table 3). None suffered from major complications. One patient had a minor wound infection, that improved after antibiotic treatment (pt. 1). Outcome in speech perception was comparable to the younger controls in three cases. One patient showed a lower outcome in speech perception, that is most likely due to mild dementia (pt. 3).

\section{Discussion}

The assessment of the perioperative risk according to the ASA classification showed no difference between G I and G II while G III was rated at a higher risk. Contrary to expectations all three groups showed no significant difference in peri- and postoperative complications or length of hospital stay. This may be due to a more selective indication for surgery in patients older than $60 \mathrm{yrs}$. An anesthesiologist checks up on seniors and patients with known major comorbidities in due time before surgery, so as to exclude patients with a high surgical risk. To date, none of the patients suggested for cochlear implantation by the otorhinolaryngologists was rejected surgery in our clinic. Chen et al. reviewed more than 400 patients older than 60 years for surgical complications and found no increase compared to younger patients reported in literature [13].

All groups benefitted significantly from cochlear implantation in everyday speech perception according to the APHAB questionnaire and audiological results.

Seniors younger than 70 years showed no difference in speech perception after CI to the younger control group. This implies that cochlear implantation for this group can be considered as well as for younger patients. With regards to speech perception, seniors older than 70 years seem to benefit marginally less than the younger ones. .

A perception for monosyllabic words of $53 \%$ and for bisyllabic words of $98 \%$ at $65 \mathrm{~dB}$ HL was achieved by G III, which is a good result after CI-Implantation. Our results correspond to those of other authors. Friedland et al. showed a slower learning effect in the older group with marginally inferior speech perception after one year [7]. Herzog et al. reported a rather flat learning curve, but attaining the same level of speech perception as the other groups after one year [5]. Lenarz et al.

Table 3. Quality of life questionnaire.

\begin{tabular}{|c|c|c|c|}
\hline & $\begin{array}{c}\text { group I } \\
40-59 \text { yrs }\end{array}$ & $\begin{array}{l}\text { group II } \\
60-69 \text { yrs }\end{array}$ & $\begin{array}{l}\text { group III } \\
\geq 70 \mathrm{yrs}\end{array}$ \\
\hline \multicolumn{4}{|l|}{ Did you have less social contact caused by hearing loss?(\% (n)) } \\
\hline yes & $59(23)$ & $100(35)$ & $88(38)$ \\
\hline no & $41(16)$ & 0 & $12(5)$ \\
\hline \multicolumn{4}{|l|}{ Do you have increased social contacts after CI implantation? (\% (n)) } \\
\hline yes & $59(23)$ & $94(33)$ & $77(33)$ \\
\hline maybe & $31(12)$ & $6(2)$ & $14(6)$ \\
\hline no & $10(4)$ & 0 & $9(4)$ \\
\hline \multicolumn{4}{|l|}{ How long do you use your CI each day?(\% (n)) } \\
\hline the whole day & $100(39)$ & $100(35)$ & $81(35)$ \\
\hline 6-8 hours & 0 & 0 & $19(8)$ \\
\hline less than 6 hours & 0 & 0 & 0 \\
\hline \multicolumn{4}{|l|}{ Do you have to use lip reading? (\% (n)) } \\
\hline no & $15(6)$ & $43(15)$ & $42(18)$ \\
\hline sometimes & $70(27)$ & $57(20)$ & $58(25)$ \\
\hline always & $15(6)$ & 0 & 0 \\
\hline \multicolumn{4}{|l|}{ Do you understand a person that is talking from behind you? $(\%(n))$} \\
\hline mostly yes & $39(15)$ & $54(19)$ & $38(16)$ \\
\hline sometimes & $56(22)$ & $46(16)$ & $58(25)$ \\
\hline never & $5(2)$ & 0 & $5(2)$ \\
\hline \multicolumn{4}{|l|}{ Can you use a telephone with your CI? (\% (n)) } \\
\hline yes & $64(25)$ & $83(29)$ & $63(27)$ \\
\hline no & $36(14)$ & $17(6)$ & $37(16)$ \\
\hline \multicolumn{4}{|l|}{ How well do you feel integrated into your family and friends after CI implantation? (\% (n)) } \\
\hline better integrated & $62(24)$ & $83(29)$ & $81(35)$ \\
\hline less integrated & 0 & $11(4)$ & $14(6)$ \\
\hline no change & $38(15)$ & $6(2)$ & $5(2)$ \\
\hline \multicolumn{4}{|l|}{ How do you describe your participation in social life after CI implantation? (\% (n)) } \\
\hline more participation & $59(23)$ & $94(33)$ & $51(22)$ \\
\hline less participation & $31(12)$ & 0 & $9(4)$ \\
\hline no change & $10(4)$ & $6(2)$ & $40(17)$ \\
\hline \multicolumn{4}{|l|}{ Would you make your decision for CI implantation again? (\% (n)) } \\
\hline yes & $95(37)$ & $94(33)$ & $81(35)$ \\
\hline maybe & $5(2)$ & $6(2)$ & $19(8)$ \\
\hline no & 0 & 0 & 0 \\
\hline \multicolumn{4}{|l|}{ Would you recommend CI implantation for people with severe hearing loss? (\% (n)) } \\
\hline yes & $95(37)$ & $100(35)$ & $81(35)$ \\
\hline maybe & $5(2)$ & 0 & $19(8)$ \\
\hline no & 0 & 0 & 0 \\
\hline
\end{tabular}




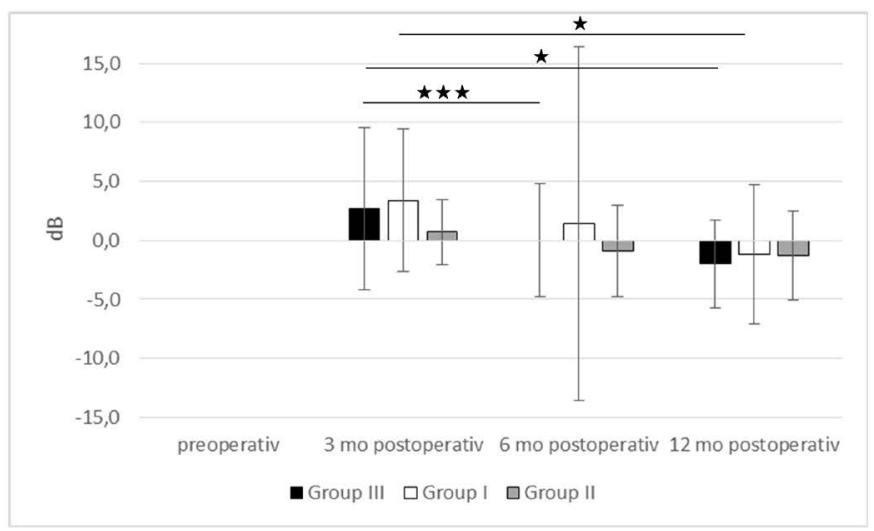

Figure 3. OLSA sentence test in noise, $* \mathrm{p}<0.05, * * * \mathrm{p}<0.01$, not marked: increase of perception preoperative - postoperative highly significant $(\mathrm{p}<0.01)$.

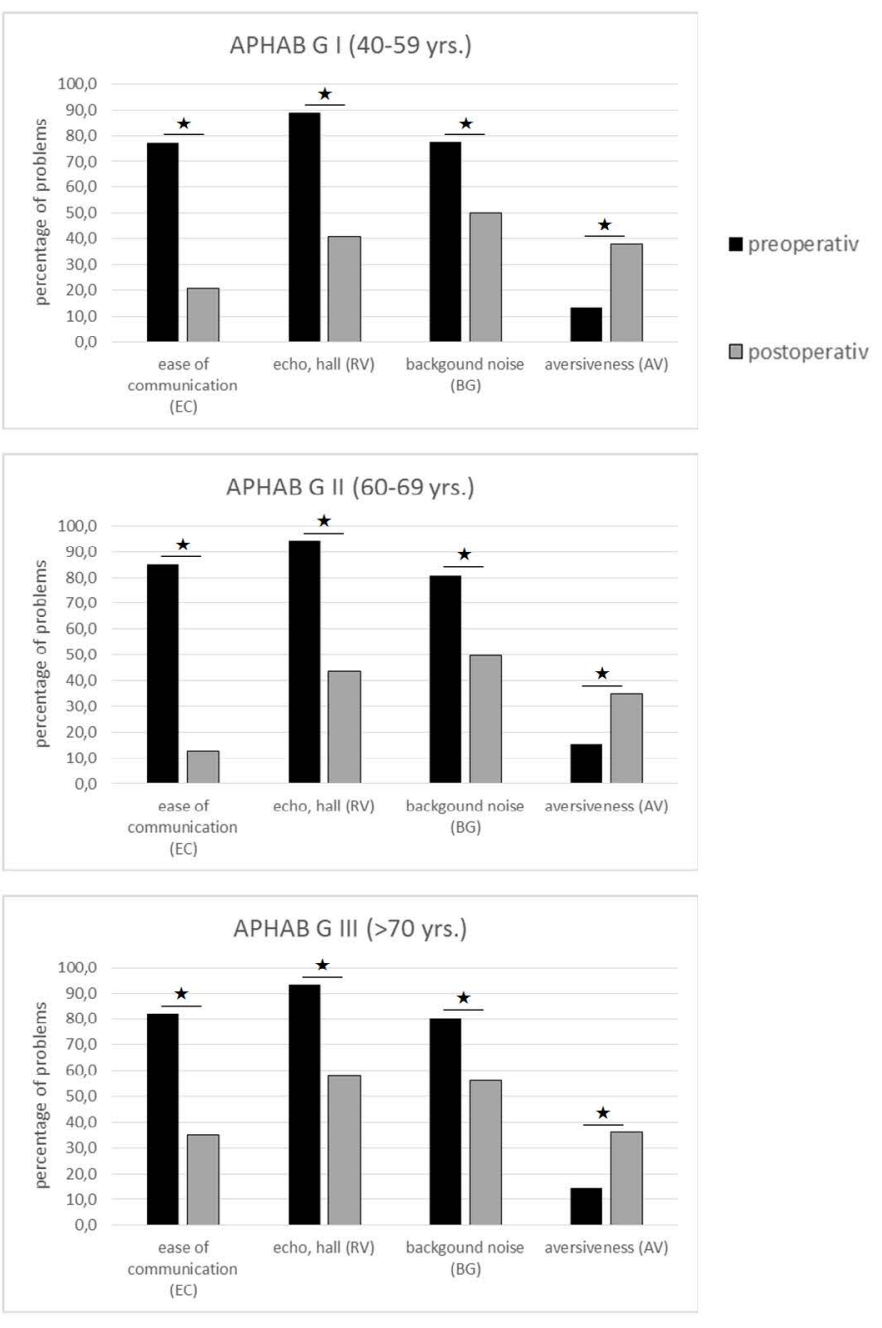

Figure 4. Abbreviated Profile of Hearing Aid Benefit (APHAB) test, ${ }^{*} \mathrm{p}<0.05$.

found an inferior result in speech perception in a complex hearing test in a noisy environment for patients over 70 years [14]. These patients showed similar results to a younger control in hearing tests without noise. Notably, age itself is not mentioned as a criterion for exclusion in literature. These results may be caused by lower cognitive skills in geriatric patients. In combination with comorbidities, e.g. loss in visual acuity, light dementia or motor impairments, speech rehabilitation definitely is more challenging. Furthermore presbyacusis seems to be caused not only peripherally due to impairment of the inner ear structures but also by central degeneration that is not impaired by CI [15]. Especially hearing in a noisy surrounding is affected by these factors, which is according to our findings in the APHAB test, the OLSA test and those of Lenarz et al. [14]. According to our QoL questionnaire, patients older than 70 years showed a higher rate of auditory deprivation. Francis et al. found a significant poorer gain in speech perception in CI recipients suffering from deprivation or depression, which may be a further explanation for the lower outcome in the elders [16].

All groups had an increase in quality of life after CI implantation. Expectations pertaining to hearing improvement after CI seem to be less demanding in elders. Compared to younger patients, quality of life studies showed a similar improvement despite an inferior outcome in hearing tests [17]. Several studies found a positive correlation between hearing loss and dementia. It has to be clarified, whether the use of hearing aids may reduce the progress of dementia $[18,19]$. Though it is well known, that social isolation improves dementia $[3,20]$, a majority of our CI recipients older than 70 yrs. reports an increase in social activity after surgery. This leads to the thesis, that CI implantation in older patients may be protective according to dementia. To strengthen this theory, further studies are desirable.

Our results imply that rising age itself only has a small impact on risk factors and development of speech comprehension in people aged 70 years and above. The patients older than $80 \mathrm{yrs}$. had a similar outcome in speech perception and complications and were comparable to those aged 70-79 yrs. Carlson et al. found a low incidence of complications peri- and postoperative in a large collective of octogenarians. However they reported an increase of anesthetic complications with increasing age [6].

Seniors between 60 and 69 years showed similar results to the younger control, being even slightly superior in postoperative speech perception. This may be caused by a more strict indication for $\mathrm{CI}$ increasing with the patient's age. According to our experience, the elders themselves are also more apprehensive to take a surgical risk. Patients older than 70 years showed an inferior audiological outcome compared to the other groups. However speech perception after CI showed a significant increase with an overall perception of 53\% for monosyllables and $98 \%$ for bisyllables - a good postoperative result. In summary we wouldn't recommend to impose an age restriction on cochlear implantation. We suggest an age adapted rehabilitation to optimize hearing. Many old CI recipients benefit from more frequent but shorter units of fitting and speech comprehension training, due to a shorter attention span and a reduced cognitive receptivity. Additionally the use of new technical features in speech processors as for example remote assistants with a protruding surface and a smaller selection of settings might be of great advantage.

\section{References}

1. Aschendorff A, Marangos N, Laszig R (1997) [Early and long-term results of rehabilitation of cochlear implant patients]. Laryngorhinootologie 76: 275-277. [Crossref]

2. Marangos N, Laszig R (1998) [Cochlear implants. Prosthetic management of deafness at the turn of the century]. HNO 46: 12-26. [Crossref]

3. Fratiglioni L, Wang HX, Ericsson K, Maytan M, Winblad B (2000) Influence of social network on occurrence of dementia: a community-based longitudinal study. Lancet 355: 1315-1319. [Crossref] 
4. Büchsenschütz K, Arnolds J, Fahimi F, Günnicker M, Lang S, et al. (2015) Surgical risk profile and audiological outcome in the elderly after cochlea-implantation. LaryngoRhino-Otol 94: 670-675. [Crossref]

5. Herzog M, Schön F, Müller J, Knaus C, Scholtz L, et al. (2003) Long term results after cochlear implantation in elderly patients. Laryngo-Rhino-Otol 82: 490-493. [Crossref]

6. Carlson ML, Breen JT, Gifford RH, Driscoll CL, Neff BA, et al. (2010) Cochlear implantation in the octogenarian and nonagenarian. Otol Neurotol 31: 1343-1349. [Crossref]

7. Friedland DR, Runge-Samuelson C, Baig H, Jensen J (2010) Case-control analysis of cochlear implant performance in elderly patients. Arch Otolaryngol Head Neck Surg 136: 432-438. [Crossref]

8. Chatelin V, Kim EJ, Driscoll C, Larky J, Polite C, et al. (2004) Cochlear implant outcomes in the elderly. Otol Neurotol 25: 298-301. [Crossref]

9. Keats AS (1978) The ASA classification of physical status--a recapitulation. Anesthesiology 49: 233-236. [Crossref]

10. Dripps RD (1963) New classification of physical status. Anesthesiology 21: 111.

11. Leung JM, Dzankic S (2001) Relative importance of preoperative health status versus intraoperative factors in predicting postoperative adverse outcomes in geriatric surgical patients. J Am Geriatr Soc 49: 1080-1085. [Crossref]
12. Cox RM, Alexander GC (1995) The abbreviated profile of hearing aid benefit. Ear Hear 16: 176-186. [Crossref]

13. Chen DS, Clarrett DM, Li L, Bowditch SP, Niparko JK, et al. (2013) Cochlear implantation in older adults: long-term analysis of complications and device survival in a consecutive series. Otol Neurotol 34: 1272-1277. [Crossref]

14. Lenarz M, Sönmez H, Joseph G, Büchner A, Lenarz T (2012) Cochlear implant performance in geriatric patients. Laryngoscope 122: 1361-1365. [Crossref]

15. Gates GA, Mills JH (2005) Presbycusis. Lancet 366: 1111-1120. [Crossref]

16. Francis HW, Yeagle JA, Thompson CB (2015) Clinical and psychosocial risk factors of hearing outcome in older adults with cochlear implants. Laryngoscope 125: 695-702. [Crossref]

17. Olze H, Gräbel S, Förster U, Zirke N, Huhnd LE, et al. (2012) Elderly patients benefit from cochlear implantation regarding auditory rehabilitation, quality of life, tinnitus, and stress. Laryngoscope 122: 196-203. [Crossref]

18. Lin FR (2011) Hearing loss and cognition among older adults in the United States. $J$ Gerontol A Biol Sci Med Sci 66: 1131-1136. [Crossref]

19. Lin FR, Yaffe K, Xia J, Xue QL, Harris TB, et al. (2013) Hearing loss and cognitive decline in older adults. JAMA Intern Med 173: 293-299. [Crossref]

20. Strawbridge WJ, Wallhagen MI, Shema SJ, Kaplan GA (2000) Negative consequences of hearing impairment in old age: a longitudinal analysis. Gerontologist 40: 320-326. [Crossref]

Copyright: (C2016 Stähr K. This is an open-access article distributed under the terms of the Creative Commons Attribution License, which permits unrestricted use, distribution, and reproduction in any medium, provided the original author and source are credited. 